\section{Eke CB Ubesie AC Ibe BC}

\title{
Challenges of childhood obesity in a developing economy: A review
}

DOI:http://dx.doi.org/10.4314/njp.v42i3.1

Accepted: 24th February 2015

Eke CB（ $(\boldsymbol{\nabla})$

Ubesie AC, Ibe BC

Department of Paediatrics, College of Medicine

University of Nigeria/University of Nigeria Teaching Hospital

Enugu

Email: chriseke2006@yahoo.com; christopher.eke@unn.edu.ng

\begin{abstract}
Background: Obesity once considered a high income country's malady is now on the rise in most developing countries particularly in urban settings. Most of these emerging economies have been reported to have different shades of under - nutrition coexisting side by side with over-nutrition. It is pertinent therefore that we determine the factors driving the increase in obesity rates in developing countries as they generally lack the infrastructure to adequately handle the associated complications.

Objectives: This communication is aimed at reviewing the burden and risk factors for obesity in children in developing countries, double burden of malnutrition, challenges including medical as well as economic costs and sustainable preventive programmes of obesity in our environment with the hope of sensitizing both the health community and policy makers of this emerging epidemic.
\end{abstract}

Methods: We searched relevant literature on the subject published only in English language or translated into English language manually and electronically. The Index Medicus, AJOL, Medline, PUBMED, and HINARI were specifically searched for the period between 1980 and 2014 and reviewed. The following key words were applied in the search: Obesity in childhood, its burden and associated risk factors, complications of obesity in childhood, double burden of malnutrition in developing countries, assessment of obesity, childhood challenges of obesity including its direct and indirect costs in developing countries as well as practical preven- tive models in developing economies.

Results: Several relevant studies were identified. The health as well as economic costs of obesity is diverse. Obesity is the major risk factor for a variety of non - communicable diseases including cardiovascular diseases, type 2 diabetes and malignancies in later life. Also obese children have higher risk of orthopaedic problems and psychological disturbances like low -self esteem and bullying. This can also lead to poor social adjustments among our teeming youths who are the bedrock of our future economy. Most of these diseases cause premature deaths in addition to long term morbidities.

Many of these obesity associated complications impose substantial burden on the health care system in developing countries with weak health systems, and if allowed unmitigated the implications are that the cost of its care may overwhelm not only the health budget but also affect the provisions of basic social amenities.

Conclusions: Preventive programmes have been shown to reduce the burden of obesity in developed countries. Dearth of data on burden of obesity and its associated complications in children and adolescents still a challenge in most developing economies. Efforts should be made to prevent childhood obesity using multi- pronged approach at population level through targeted education, sustainable interventions related to healthy nutritional practices as well as physical activity promotion.

Key words: Challenges; Obesity; Children; Developing Economies 


\section{Introduction}

The World Health Organization (WHO) defined obesity as a condition of abnormal or excessive fat accumulation in adipose tissue resulting in impairment of health ${ }^{1}$.

Obesity has been known to man since the middle ages; during the Renaissance of Europe and the Ancient East Asian Civilization when it was regarded as a mark of affluence and wealth and was relatively common among the elites ${ }^{2}$. However the famous Hippocrates of Cos noted the danger that it portended and wrote that "corpulence is not only a disease in itself but the harbinger of others" .

\section{Burden}

Obesity earlier considered a problem of high income countries is now on the rise in most low and middle income countries particularly in urban settings ${ }^{4}$. The world including developing countries is facing a global epidemic of not only childhood but adulthood obesity ${ }^{5}$. Overall more than $10 \%$ of the world's population is obese $^{1}$.

The World Health Organization (WHO) is alarmed and has warned that childhood obesity is one of the most serious global public health challenges of the $21^{\text {st }}$

century. Generally, obese children and adolescents are at increased risk of developing various health problems mainly non- communicable diseases like type 2 diabetes, cardiovascular diseases in addition to psychological disturbances ${ }^{6}$.

In 2012, more than 40 million children under the age of five were reported to be overweight/obese globally. Of these more than 30 million (>75\%) live in developing countries and 10 million in developed countries ${ }^{1}$.

The rate of overweight and obesity among preschool African children has doubled over the past two decades, from 4 to $8.5 \%$ between 1990 to 2010 and is expected to hit $12.7 \%$ by the year $2020^{7}$. Asia, excluding Japan has also reported a dramatic increase in the rate of obesity over the same period as in sub - Saharan Africa. Though most countries are still combating poverty and hunger, globalization has made societies wealthier, and wealth and weight are linearly related. Similar increase in prevalence has been observed in the Latin America and the Caribbean ${ }^{8}$. In the United States, over the last 3 decades childhood obesity has tripled and by 2008 nearly $7 \%$ of children were obese ${ }^{8}$.

In Nigeria there are limited data on prevalence of overweight and obesity because of lack of representative data from composite geopolitical regions. So far the available studies on overweight and obesity in Nigerian children have used different diagnostic criteria but highlighted the high prevalence of body weight disorders. Opara and colleagues $(2010)^{9}$ reported an obesity prevalence of $11.3 \%$ among primary school children in Uyo, South South Nigeria while Yusuf and co - workers ${ }^{10}$ found obesity and overweight prevalence of $0.84 \%$ and $1.98 \%$ respectively among adolescents in Kano metropolis, North West, Nigeria. In a more representative study in Benue State, North Central Nigeria, Denladi
Musa et $\mathrm{al}^{11}$ studied 3240 children aged 9-16 years and reported obesity prevalence of $1.8 \%$ and overweight $9.7 \%$ respectively. The obesity pandemic has spared no age groups even among children with haemoglobinopathy previously thought to be underweight due to their chronic anaeamic state, obesity rate of $2.5 \%$ among children aged 2-15 years has been reported in Lagos, SouthSouth Nigeria ${ }^{12}$.

\section{Predisposing Factors}

Obesity reflects a complex condition which is influenced by a wide range of genetic, metabolic, cultural, environmental, socioeconomic, and behavioral factors. It is the convergence of these forces, biological and technological that has produced the current obesity epidemic $^{13}$, we see today. Scott and colleagues ${ }^{14}$ designed a causality continuum model for obesity in sub -Saharan Africa - the theoretical framework reviewed incorporates distal, intermediate and distal forces as pivotal to the increase in overweight and obesity rates in sub- Sahara Africa. These forces, while presented singly, interact in several ways, with distal forces such as globalization directly impacting on forces at other levels such as occupation and diet. The distal forces incorporated include globalization and urbanization, with reduced physical activity, cultural perceptions of weight, built environment and socioeconomic class at the intermediate levels ${ }^{14}$.

Caloric intake, physical inactivity and genetics lie at the distant level and reflect the health behaviors most directly related to overweight and obesity while the environment modifies how the genes are expressed, placing genetics inside the causality continuum that produces overweight and obesity in humans ${ }^{14}$.

\section{Genetic Linkage}

Genes have been known to influence an uncontrollable urge to eat; with likelihood of physical inactivity; an increased capacity to store fat; and a minimal ability to expend dietaryfat ${ }^{15,16}$. Following epidemiological surveys childhood obesity has been shown to be genetically linked to metabolic syndrome ${ }^{16}$. Over the last decade large scale genome-wide association studies (GWAI) have identified some of the genetic variants associated with obesity in children of European and Hispanic ancestry respectively. ${ }^{16}$

In general, genes interact with environmental factors to produce overweight and obesity in at risk individuals. This relates to the fact that exposure to under nutrition in early life, or in utero, may increase the risk of obesity development in later life owing to epigenetic changes in metabolic function. ${ }^{17}$

This "thrifty gene" hypothesis or fetal programming postulates that due to dietary scarcity during human evolution people are prone to survive during such periods and when such individuals find themselves in environment with abundance of foods they will subsequently acquire excess fats with the tendency to become obese with its attendant complications. ${ }^{17}$ Hence, many parts of 
the developing world may be vulnerable to increases in obesity, given the high prevalence of under nutrition among the poor, coupled with the rapid introduction of caloric-dense, more affordable "westernized" diets and living in a mechanized world with little or no physical activity $^{17,18}$.

\section{Early Life Risk Factors}

a. Maternal obesity: The peri- conception period is a critical period of opportunity when exposure of the fetus could predict risk of obesity in later life for the offspring $^{19}$. Maternal obesity is one of the strongest and most reliable predictors of obesity of children in later life.

Infants born to overweight mothers are more likely to be born large for gestational age and are at increased chances for the development of obesity and its related complications including type 2 diabetes mellitus in later life. Babies born to mothers with impaired glucose tolerance during pregnancy are more likely to be macrocosmic and have higher body fat at birth and subsequently be at increased risk for becoming overweight with its attendant health consequences.

Hence there is need for optimal maternal nutrition before conception and application of adequate weight loss interventions in overweight and obese women during the periconceptional period in order to obtain favourable outcomes ${ }^{15,20}$. The application of dietary restrictions in obese mothers during the peri-conceptional period may suppress the programming of obesity.

b. Maternal Smoking: It is known that maternal smoking during pregnancy results in low birth weight babies. However for reasons that are not clearly understood offsprings of women who smoke may be more predisposed to be obese in later life compared to their counterparts who their mothers did not smoke and this appears to be dose - dependent. ${ }^{21}$

\section{Infancy Risk Factors}

In the first year of life the primary determinants of obesity in later life include rapid weight gain and the type and duration of infant feeding.

a. Breastfeeding: Recentmeta-analyses showed that babies who are breast fed are associated with a $13-22 \%$ reduced odds for overweight or obesity in childhood and in later life and there is an associated dose dependent response effect based on the duration of the breastfeeding in the infant $\mathrm{t}^{22,23,24}$.

b. Early Introduction of Solids: Studies have shown that introduction of solids too early may predispose a child to chronic diseases such as islet cell auto immunity (the preclinical condition that causes type 1 diabetes) and obesity ${ }^{25,26}$.

Recent studies show that among infants that were not breastfed the introduction of solid foods before age 4 months results in increased obesity by age 3 years (by up to 6folds) while in formula -fed infants evidence of obesity was observed as a 0.4 unit increase in body mass index (BMI) $\mathrm{z}$ - score at age 3 years. In contrast, infants that were breastfed up to 4 months the timing for the introduction of the solid food was not associated with evidence of obesity ${ }^{27,28}$.

c. Sleep duration: The well known association between growth hormone and sleep led to the hypothesis that sleep patterns may be associated with the saltatory growth spurts ${ }^{29}$. In children it has been shown that an inverse association occurs between sleep duration and obesity. The longer the sleep duration in hours particularly nocturnal sleep the higher the risk of obesity. ${ }^{30}$

d. Early child care (Day care) attendance: The growing use of early child substitute care especially prenursery/nursery schools has raised awareness among health officials of the special role that child care settings play in determining children's eating and activity behaviour $^{31}$. Most of the privately owned schools approved by government agencies do not have facilities including play grounds for variety of physical activities for the children.

\section{Risk factors in early childhood through pre-school}

Beyond the first year of life, a couple of risk factors have been observed to be linked with obesity in later life including:

a. Television Viewing: Among the school - aged children, observational and experimental research have shown that television viewing is positively associated with risk of overweight. Among preschool aged children, Denninson et $\mathrm{al}^{32}$ found that the number of hours a child spends watching television (TV) is associated with increased risk of obesity. During periods of commercial TV viewing children are exposed to a lot of stations showing cartoons with commercial advertisements on variety of branded high calorie, nutrient -poor foods and drinks as well as fast food restaurants. Children who watched cartoonswith commercials are more likely to prefer the products advertised than children who watched the same cartoon but were not exposed to commercials ${ }^{33}$. These findings suggest that food advertisement can affect children's food preferences and could contribute to greater intake of high calorie dense, nutrient poor foods thus fueling the obesity pandemic.

b. Sleep: Short sleep duration persists as a potential risk factor for obesity in children. However the actual mechanism is uncertain. In order for short sleep duration to produce weight gain, short sleep duration could either increase energy intake and/or reduce energy expenditure. Reduced sleep has been shown to decrease plasma leptin levels, increase plasma ghrelin and cortisol levels, alter glucose homeostasis, and activate the orexin system, all of which impact the regulation of appetite ${ }^{34}$. Lack of sleep may result in weight gain and obesity by increasing the time available for eating and by making the maintenance of a healthy lifestyle more difficult ${ }^{35}$.

c. High Consumption of Sugar Sweetened Beverages: 
The consumption of sugar sweetened beverages particularly carbonated soft drinks (which contain simple sugars either as sucrose or high fructose corn syrup as source of fructose) has been linked with the epidemic of overweight and obesity ${ }^{36,37}$. Children start drinking sugar-sweetened beverages at a remarkably young age and such consumption increases even to young adulthood. High fructose corn syrup (HFCS) is found in all foods containing caloric sweeteners including majority of the soft drinks, fruit drinks, canned fruits, dairy desserts and flavored yogurts, most baked goods, many cereals, and jellies ${ }^{36}$.

The consumption of fructose -sweetened beverages increases adiposity more than the consumption of either sucrose or other artificially sweetened beverages ${ }^{38}$. This is partly due to a shift of substrate use to lipogenesis. Both sugars i.e. HFCS and sucrose are not interchangeable. But it is important to note that HFCS also contains glucose. Fructose, may lead to greater weight gain and insulin resistance by elevating plasma triacylglycerols and subsequently decreasing the production of insulin and leptin in peripheral tissues - not suppressing ghrelin thereby decreasing signaling to the central nervous system from insulin and leptin - and possibly ghrelin. However the glucose (sugar) composition of fructose is similar to that of sucrose. Whether HFCS is more detrimental to weight gain than other types of sugars is not fully elucidated and may require further studies ${ }^{39,40}$.

\section{General Risk Factors}

a. Culture: Several reasons have been proposed for the differences in the burden of obesity among groups including genetics, physiology, culture, socioeconomic status, environment and interactions among these variables $^{41}$. Obesity however is viewed differently across cultures, and perceiving it as a disease is more of a 'Western' phenomenon.

In most cultures obesity has been historically been associated with wealth, health and happiness. ${ }^{42}$ The cultural norms may serve to catalyze the increases in overweight and obesity and act as a significant barrier to success of any intervention program. Culture may play a role in shaping parental perception of their children's health status e.g. In some cultures like the Hispanics in South America, Igbo ethnic nationality in Nigeria mothers may view thinness as a reflection of poor health and undernutrition. Thus, they may encourage their children to eat more and accumulate more fat.

b. Socioeconomic status (SES): There is a positive relationship between SES and obesity in developing countries as obesity is more of the problem of the wealthy in such environments. In addition a positive association between higher SES and obesity appears to be an inverse relationship as one moved from countries with lower human development index (HDI) to countries of higher $\mathrm{HDI}^{43}$.

Wang et $\mathrm{al}^{44}$ reported that there may be a bidirectional causal link between SES and obesity, because obesity may adversely affect one's opportunity for education, occupation, and marriage.

In many sub - Saharan African settings obesity is a disease of the elite class with better income and educational attainment. Similar experience has been reported in other emerging economies like Nigeria ${ }^{45}$ and Bangladesh ${ }^{46}$ while a study in Brazil did not report any association between obesity and SES ${ }^{47}$.

c. Urbanization: Currently rural - urban migration could be due to a complex of "push" factors including industrialization, insecurity about food security in rural areas, search for refuge/safe haven from conflicts including insurgency as in many countries in Sub- Sahara Africa like Nigeria, Somalia, Kenya to mention among others and environmental degradation, in addition to pursuit for 'better -life' like opportunities for employment, social amenities and better quality of life..$^{14,48}$

In addition several "push" factors operating in many rural settings, as changes in trade and food production due to globalization and the desire to leave subsistence farming, make rural life less desirable. ${ }^{48}$ Urbanization could offer economic and social advantages to some but many migrants languish in urban centres, resulting in rising income in- equalities in some sub- Sahara African settings. In the centre of all these are our children who are either moving with their parents/caregivers or are born in the course.

Urban relocation by rural dwellers could predispose them to abrupt changes in diet and physical activity levels for reasons related partly to globalization. While in rural areas, many people grow and consume traditional staple foods that are low in fat and calories but high in fibres and carbohydrates and micronutrients those living in urban areas can afford and buy variety of high energy dense drinks and "junk" foods with the likelihood of being obesogenic in nature.

d. Globalization: This is a process characterized by the growing inter-dependence of all particularly in the areas of the integration of economies, culture, technology and governance.

Several emerging/developing countries have benefitted tremendously from richer economies particularly in the area of food security and nutrition via increased employment opportunities, productivity and better quality of life $^{14}$.

Free trade and commerce have led several countries in developing countries to the current nutrition transition where they shift away from their usual traditional production and consumption of local staple foods rich in whole grain, fruits and vegetables to importation of processed obesogenic western staples that are "nutrient poor' energy dense, high fat, and above all low cost particularly among those resident in urban areas ${ }^{49}$.

\section{e. Sedentary lifestyles/Reduced Physical activity:}

Levels of physical inactivity are rising globally with its implications for the prevention of non -communicable diseases including obesity and its related metabolic syndrome in later life ${ }^{50}$. This is primarily due to increasing use of mechanization ${ }^{14}$. Among children there appears to be general decline in physical activity owing to less trekking and down-playing of physical education in our educational systems. Many private schools are being 
licensed without playgrounds. In some cities notable recreational/amusement parks are now been given-up for 'exotic' housing estates and shopping malls for the rich. Also insecurity particularly in urban settings in the guise of kidnappings, armed robbery, rape and the big one insurgency/sectarianism have all made the teeming population of our children to be locked indoors after school hours by apprehensive parents who are afraid of the unknown. Thus limiting the time and liberty they have for adequate and variable physical exercise needed to burn off some stored energy. The resultant effect is that urban children will be confined to their homes and given the opportunities to get glued to screens in the form of television, computer games and consumption of energy dense foods/drinks making the vicious cycle of obesity to continue

The World Health Assembly in 2004 recommended that each member state should develop national physical activity plans and policies to increase physical activity levels in their population ${ }^{51}$.

f. Drug use: Several herbal medications have been reported to be in use in some settings in Africa like in Western Sahara (also known as Sahrawi) where they practice traditional fattening involving periods of ritual overfeeding and use of appetite enhancers and traditional medication (suppositories composed of a mix of dates, seeds, and medicinal plants that are believed to increase peripheral fat accumulation), ${ }^{52}$ in addition to prolonged use of some certain orthodox medications including insulin, antipsychotics, selective serotonin reuptake inhibitors, tricyclic antidepressants, anticonvulsants/mood stabilizers and prednisone that that have been implicated in weight gain/change in body composition.

\section{The Double Burden of Malnutrition in Developing Economies}

The obesity epidemic is particularly disturbing in developing countries where nutrition transition in addition to continuing infectious diseases, poverty and ignorance propel the dual burden of under-nutrition and obesity within the same households. The synergetic links among infectious diseases, under-nutrition and overweight/ obesity are manifest across the lifespan.

Double burden malnutrition exists in developing countries with varying degrees of public health importance owing to the uneven socio - economic development within the segments of the society. Middle and low income countries continue to face the challenges of infectious diseases and under- nutrition in the face of a rapid rise in non- communicable diseases including obesity and overweight. Obesity co-existing with varying degrees of under nutrition has been reported even in the fast emerging nations like India ${ }^{53}$

In Nigeria, under-nutrition accounts for $>50 \%$ of under five mortality rate (142 per 1000 live births) directly or in-directly $\left(2^{\text {nd }}\right.$ largest world contributor). At the same time there is rising rates of overweight/obesity within the same communities with different shades of under nutrition in Nigeria. ${ }^{9,11}$
The challenge for developing economies is how best to confront the 'double burden' of malnutrition: undernutrition; and overweight and obesity, and how to ensure optimal childhood nutrition in a fast changing society. No action will lead to escalation with the short and long term health consequences.

\section{Secondary Causes of Obesity}

Some of the following have also been implicated in childhood obesity in both developed and developing countries. They include:

1. Endocrinopathies: Cushing syndrome, hyperinsulinism, hypothyrodism, growth hormone deficiency.

2. Rare Genetic syndromes (Syndromic Obesity): Prader Willi Syndrome, Turner Syndrome, Beckwith Wiedmann, Lawrence - Moon Biedl, Melano cortin - 4receptor gene mutation . Leptin or Leptin Receptor gene mutation., Alstrom syndrome ,Carpenter syndrome etc.

3. Psychological disorders: Binge eating disorder and night eating disorder. $54,55,56$

\section{Possible Pathophysiologic Mechanisms}

Further to the previously listed causes of obesity several hormones, genetics, neurotransmitters and receptors in the hypothalamus and its adjourning structures have been shown to contribute in the regulation of appetite as well as body weight. ${ }^{57}$ Some of agents have effect on long-term control of energy intake (e.g. leptin, neuropeptide) while others have a short-term impact on energy intake (e.g. Ghrelin, insulin, and cholecystokinin). ${ }^{58}$

\section{Assessment of Obesity in Children}

Accurate assessment of obesity in children is a critical as well as challenging aspect of present day paediatric practice globally. The measurement of body composition provides more detailed information about nutritional status than the measurement of stature and weight alone. Recent technological development has led to the availability of several instruments for assessing body composition including densitometry, dual energy absorptiometry (DEXA), tracer dilution techniques neutron activation, ultrasound, magnetic resonance imaging, computerized tomography scan and bio- electric impedance analysis. Most of these techniques are complex, expensive and not practicable for routine clinical use and hence are restricted mainly to research.

Anthropometric measurements are most commonly used in clinical settings and epidemiological studies as indirect methods of estimating fat mass. Weight and BMI are generally applied. The BMI is standard and reliable indicator of overweight and obesity. It is also the preferred measure for evaluating obesity among children and adolescents $2-19$ years of age. It expresses the weight for height relationship as a ratio i.e. weight (in kilograms)/height in meters ${ }^{59}$.

Its strengths include the following: It is easily obtained, correlates strongly and weakly with body fat and height respectively. ${ }^{60}$ Above all the BMI correctly identifies the fattest individuals with acceptable accuracy at the upper 
end of the distribution (e.g. $\geq 85^{\text {th }}$ or $\geq 95^{\text {th }}$ percentile for age and gender). Using BMI, obesity is defined as BMI that is $\geq 95^{\text {th }}$ percentile using either the United States Centers for Disease Control and Prevention (CDC) or the World Health Organization growth charts.

However for children $\geq 2$ years of age the weight for recumbent length percentile from the year $2000 \mathrm{CDC}$ or WHO growth charts should be regarded as appropriate for evaluating weight relative to linear length. But generally the term obesity is avoided in these age group rather weight for length percentiles $\geq 95^{\text {th }}$ identifies these as overweight. ${ }^{61}$

The WHO standard growth charts are generally preferred in infants aged $0-24$ months due to the fact that they establish growth of the breastfed infant as the norm for growth, provides better description of physiological growth in infancy and the standards are based on a high quality designed explicitly for growth charts ${ }^{62}$.

For screening purposes especially field work the International Obesity Task Force (IOTF) charts could be applied. It is not meant for routine clinical use. It is important to note that as a quick screening tool the IOTF chart has got comparable sensitivities and specificities as the regular BMI charts.

For research purposes the age specific z- scores or standard deviation (SD) scores are generally used for extreme values of anthropometric measures. A BMI online calculator is available: http;//www.kidsnutrition.org/ bodycomp/bmiz2.html. ${ }^{59}$ The WHO - Anthro - and anthro -Plus internet calculator are also in use online.

Other useful anthropometric tools in the assessment of overweight and obesity in children is skin fold thickness and waist circumference measurements.

Other general components of nutritional assessment in the evaluation of obesity include the medical history, dietary and physical activity assessment.

The challenge for most countries in sub- Saharan Africa is the lack of adequate local clinical tools and representative data to assess the burden of obesity in our environment. Most of the tools we have for practice are either from the Centers for Disease Control, United States or the WHO charts which may have some variations with regards to our local population and may either under - or over-estimate the risk of childhood obesity in our setting.

\section{Challenges of Obesity in a Developing Economy}

Obesity is a public health and policy problem because of its prevalence, costs and health effects. ${ }^{63,64}$ The health implications of obesity are multi - systemic and legion. However most of them may not be prevalent in the paediatric age groups but if childhood obesity is not adequately controlled, these children will eventually become obese adults and ultimately develop chronic complications with their attendant costs.

It is not certain whether there are differences in- terms of the frequencies of these medical complications between obese children in developing economies and those living in developed countries. Hopefully with the upcoming of quality systematic reviews and meta- analytic studies on the burden of obesity in our setting answers to these very important operational research questions may become obvious over time.

However, what is certain is that most developing countries particularly in Africa have weak health systems that are unable to cope with the double burden of infectious diseases and chronic diseases. In most Africa settings there no national chronic disease policy to deal with this burden of chronic diseases adequately, many have just got a national health policy. Most of the countries in developing countries have been shown to have high rates of disabilities and death rates due to chronic diseases such as diabetes, hypertension and stroke mainly in the last two decades straining the health systems and these have been attributed to changing behavioural practices (e.g. sedentary lifestyles and diets high in saturated fats, salt and sugar).

Experts have recommended a three - prong approach to dealing with the burden:

(a). Epidemiological surveillance;

(b). Primary prevention (preventing disease in healthy populations); and

(c). Secondary prevention (preventing complications and improving quality of life in affected communities) ${ }^{65}$. These efforts should be made to control and begin to reverse the rising trend of childhood obesity. These medical complications include:

(a). Endocrine/Reproduction System: Insulin resistance (type II diabetes mellitus, metabolic syndrome), menstrual disorders, polycystic ovarian syndrome etc;

(b). Digestive system: Non-alcoholic fatty liver diseases (NASH), cholelithiasis, gastro-esophageal reflux disease (GERD).

(c). Respiratory system: Obstructive sleep apnoea (OBSA), obesity hypoventilation syndrome, asthma. It is important to note that asthma severity, however, does not seem to be altered by obesity, leaving open the possibility that weight - related but not non-asthmatic airflow limitations are being misdiagnosed as asthma in some obese children.

(d). Central nervous system: Idiopathic intracranial hypertension.

(e). Psychosocial: Distorted peer relationships, poor self esteem, anxiety, depression.

(f). Musculoskeletal system: slipped capital femoral epiphysis, tibia vara (Blount's disease), spinal complications and acute fractures.

(g). Integumentary system: Furanculosis intertrigo (h). Urology/Renals: Sub- nephritic proteinuria, glomerulomegaly, microalbuminuria - chronic kidney disease. Focal segmental glomerulosclerosis is the ultimate finding in morbid obesity.

(i). Nutritional Deficiencies: lower levels of vitamin D and iron deficiency. ${ }^{54,55,66,67}$

(j). Malignancies: The association between obesity and cancer remains uncertain compared to that for diabetes and cardiovascular disease. This may partly be due to the fact that cancer is not a single disease but a collection of individual diseases. In 2007 the World Cancer Research Fund and the American Institute for Cancer 
Research expert panel reported that there was adequate evidence supporting a link between obesity and cancers of the esophagus, pancreas, colon and rectum, breast, endometrium, and kidney, and a probable association between obesity and gallbladder cancer. Though these are all diseases arising in obese adults, efforts should be made to control/ prevent childhood obesity from spilling over to adulthood ${ }^{68}$.

(k). Social Stigmatization: This is of major concern in older children and adolescents. Obesity can lead to social stigmatization and disadvantages in employment and marriage and association with poor personal hygiene. Some adolescents have been reported to have inflicted serious injuries to themselves and in some extreme cases committed suicide as a result of being bullied for one reason or the other ${ }^{69}$.

\section{Direct and Indirect Costs of Obesity}

The health and social consequences of obesity have over - shadowed the economic cost to society and to the individual. The costs implications of obesity on health and well-being are beginning to raise global as well as political awareness that individuals, communities, nations, and international organizations like World Health Organization must take urgent measures to stem its rising tide. These challenges include both direct medical as well as indirect costs.

\section{Direct costs}

Costs arising from outpatient and inpatient health care services (including surgery), laboratory and radiological tests, physiotherapy, drug therapy, etc. Managing obesity and its related conditions cost billions of dollars each year. One United States estimate, projected that $\$ 190$ billion was spent on obesity-related health care expenses in 2005-double previous estimates. For developing countries without health insurance policies for majority of the population including children. Caregivers when they present with their children usually 'pay out of pocket'. Also in most cases there are no available national data on economic costs of obesity complications treatments. ${ }^{68,70}$

Health related quality of life: Studies of the effect of obesity on specific health outcomes such as diabetes or depression provide just a tip of the ice- berg on the spectrum of impact of obesity on health and well-being. According to the World Health Organization, health is not just the absence of disease or infirmity but a state of holistic well being. Hence this health-related quality of life (HRQoL) integrates the effect of obesity physical, psychological, and social functioning and obesity has been reported to impact on them either directly or indirectly.

School absenteeism: Owing to prolonged period of ill health in some obese children arising from complications of obesity like slipped capital femoral epiphysis some school days could be lost with its attendant impact on academic performance.

Poor academic performance: Days lost due to illhealth/hospitalization, poor self esteem arising from stigmatization by peers and the belief that obese children are generally lazy all could impact on the overall academic performance of obese children.

\section{Indirect costs}

Are "resources forgone as a result of a health condition," and they include:

Value of lost work: strictly involve days missed from work meaning its costs to both employees (in lost emoluments) and employers (in work not done or completed). Obese employees miss more days from work due to short-term absences, long-term disability, working at less than full capacity (termed presenteeism) compared to their counterparts. However, these may indirectly apply to children when they are sick and probably hospitalized and their parents/caregivers may apply for excuse duty to take care of them.

Other aspects of indirect costs of obesity like life insurance premiums and lower wages may not directly apply to children since by law they are not licensed to work. ${ }^{70}$ Prevention has been shown to be cost effective compared to treatment, both in terms of economic and individual costs. Hence health care providers and policy makers should educate the public adequately on the importance of obesity and its prevention, and develop effective policies and programmes to prevent obesity.

\section{Prevention of obesity in children Pregnancy}

In a cross sectional study of 232 preschoolers in Brazil, mother's obesity [OR $=3.12(95 \% \mathrm{CI}, 1.41-6.91), \mathrm{P}=$ $0.01]$, weight gain of more than $0.85 \mathrm{~kg} /$ month in the first four months of life [OR $=2.16(95 \%$ CI 1.01-4.64), $\mathrm{P}=0.04]$ and lower per capita income [OR $=0.32(95 \%$ CI 0.13-0.79), $\mathrm{p}=0.01]$ remained significant predictors of obesity after multivariate adjustments. ${ }^{71}$ It is therefore imperative that obesity prevention in children should start during conception. There is need to normalize body mass index of potential mothers before pregnancy. During pregnancy, adequate maternal nutrition including micronutrient supplementations need to be ensured. Pregnant mothers should avoid smoking and other preventable risk factor for small for gestational (SGA) addressed. Studies have linked low birth weight babies with risk of obesity later in life as a result of biological programming. Moderate exercise as tolerated should be maintained. In gestational DM, provide meticulous glucose control.

\section{Post-partum}

Breastfeeding is associated with reduced incidence of obesity in childhood and later in life. In a systematic review of nine studies with more than 69,000 participants, Arenz et $\mathrm{al}^{22}$ showed that breastfeeding significantly reduced the risk of childhood obesity [AOR 0.78, $95 \%$ CI $(0.71,0.85)]$. The authors also reported a dosedependent effect of breast-feeding duration on the prevalence of obesity in four studies ${ }^{22}$. Sadly the reported 
average exclusive breastfeeding rate in infants $<6$ months of age in Nigeria is $16.4 \%$ (95\%CI: $12.6 \%$ $21.1 \%$ ) and even lower $(7.1 \%)$ in their 5th month. ${ }^{72}$ Strategies that promote, protect and support breastfeeding are therefore, critical in reducing the obesity incidence around the world.

\section{Infancy}

Beyond the immediate post-partum period, economic pressures on families put undue pressures on working mothers and fathers. This has resulted in improper use of breast milk substitutes and complementary feeds. The higher protein content of infant formula causes rapid weight increase in the first of year of life with attendant obesity risk $^{73}$. It is therefore, imperative that nutrition education on adequate, appropriate and safe complementary feeds be provided for mothers and potential mothers. The nutrition education should include merits and demerits of home-made versus commercial complementary feeds, need for micronutrients supplementation and fortifications; and importance of age-specificity and enough flexibility.

\section{Family}

The growing child should be exposed to a wide variety of foods while limiting sweetened beverages to the barest minimum. It is advised that families eat meals together in a fixed place and time. Meals especially breakfast should not be skipped. Regular vegetables and fruits should be served at meals. Portion control such as use of small plates may be required for some children. Judicious use of technologies to do work at homes is recommended. Children should be allowed to wash their clothes and dishes instead of using machines.

\section{Physical activities}

The WHO states that $60 \%$ of the world's population does not obtain the level of physical activity recommended for health benefits with rates varying from 17 to $91 \%$ in developing countries ${ }^{74}$. It is postulated that physical activity protects individual from development obesity by increasing energy expenditure and resting metabolic rate and leading to favourable fuel utilization $^{75}$. The American Academy of Pediatrics recommends avoiding television and computers in children younger than 2 years $^{76}$. Children 2-18 years of should have less than 2 hours/day of "screen time" (television, video games, computer), and televisions should be removed from children's bedrooms.

\section{Schools}

In the school environment, minimum standards for physical education, including 30-45 min of strenuous exercise 2-3 times weekly should be mandated.

Balanced school meals need to be provided as part of school health program. Discourage junk foods, sugary beverages in the children's lunch pack and encourage addition of fruits. Fast-food joints should not be located close to schools.

\section{Community}

The cultural perceptions and norms that views excessive weight gain in children as a sign of adequate nutrition should be discouraged.

\section{Government and regulatory agencies}

They need to provide financial incentives to industry to develop more healthful products and to educate the consumer on product content. Appropriate laws and regulations that will influence advertising and distribution of non-healthy foods need to be enacted. There should be outright ban of advertising of fast foods directed at preschool children while restricting advertising to schoolaged children. Other measures include taxation and pricing to promote or limit consumption of foods. Government can also assist in changing built environment (building parks, walk ways) and in urban planning.

\section{Health care setting}

It is important that weights and heights of children are routinely monitored. The body mass index (BMI) Calculated and plotted 6 monthly or at least yearly. The health care providers should discuss the benefits of increased physical activity and decreased sedentary activity with caregivers; as well as encourage them to promote healthy eating habits at family levels.

\section{International collaboration}

Like tobacco addiction, obesity does not observe national boundaries and is deeply connected to issues of globalization. It will be necessary to engage policymakers and regulators at the international level, asking questions related to governance as well as those related to public health infrastructure, inequality and inequity ${ }^{77}$.

\section{Treatment principles}

Therapies often combine diet, exercise, behavior modification, medications, and rarely, surgery. Medical management of obesity in children include dietary (portion control), increase physical activity, pharmacotherapy. Evaluation of the overweight/obese child requires compassion. The dietary practices, family structure, and habits need to be explored. Any underlying secondary cause (genetic or hormonal) should be excluded. Most successful approach requires substantial lifestyle changes that include increased physical activity and altered eating habits. Initial goal should be weight maintenance rather than reduction. Weight loss should be attempted only in skeletally matured children or in those with serious complications at weight loss goal of $0.5 \mathrm{~kg}$ or less per week. Once a $10 \%$ reduction in weight is achieved, the weight should be maintained for 6 months before further weight loss is attempted. Medications such as Orlistat (an intestinal lipase inhibitor), has been effective in adolescents older than 12 years of age. Octreotide has 
shown promise for weight control in children with hypothalamic obesity ${ }^{78}$. Dietary supplements are of questionable efficacy. One of the goals of treatment will be to evaluate for the presence of complications and manage accordingly: Hypertension, DM, PCO syndrome.

Surgery is indicated if unsuccessful with prior organized weight loss attempts or BMI of 40 or $>$ with some obesity related health problems or $\mathrm{BMI} \geq 35$ with type 2 diabetes mellitus, obstructive sleep apnoea, OSA, pseudo- tumor or $\mathrm{NASH}^{79}$.

\section{Conclusion}

Preventive programmes have been shown to reduce the burden of obesity in developed countries. Dearth of data on burden of obesity and its associated complications in children and adolescents still a challenge in most developing economies. Efforts should be made to prevent childhood obesity using multi- pronged approach at population level through targeted education, sustainable interventions related to healthy nutritional practices as well as physical activity promotion.

\section{Conflict of interests: None}

Funding: None

\section{References}

1. World Health Organization - Obesity and overweight Fact Sheet Nº311, Updated August, 2014. Available from: http://www. who.int/mediacentre/factsheets/ fs $311 /$ en. Accessed: $1^{\text {st }}$ October, 2014.

2. Obesity. Available from: http:// www.en.m.wikipedia.org/wiki/ obesity. Accessed: 1st October. 2014.

3. Hasam DW, James WP. Obesity. Lancet 2005;366:1197 - 1209.

4. Bloomgarden Z. Prevention of obesity and diabetes. Diabetes Care 2003;1: 3172 - 3178.

5. Global strategy on diet, physical activity and health: Childhood overweight and obesity. Available from:http://www.who.int/diet/ physicalactivity/childhood/en. Accessed: 1st October, 2014.

6. Dehghan M, Akhtar-Danesh N, Merchant AT. Nutrition Journal 2005;4:24. Available from:http:// www.nutritionj.com content/4/1/24. Accessed: 1st May, 2013.

7. De Onis M, Blossner M, Borghi E. Global Prevalence and trends of overweight and obesity among preschool children, Am J Clin Nutr 2010; 92:1257- 1264.

8. Child obesity: Too many kids are too heavy, too young. Available from: http://www.hsph.harvard. edu/obesity - prevention-source/ obesity- trends-in-children. Accessed: $1^{\text {st }}$ October, 2014.

9. Opara DC, Ikpeme EE, Ekanem US. Prevalence of stunting, underweight and obesity in school aged children in Uyo, Nigeria. Pakistan Journal of Nutrition 2010;9 (5): 459 - 466.

10. Yusuf SM, Mijinyawa MS, Musa BM, Gezawa ID, Uloko AE. Overweight and obesity in Kano, Nigeria. J Metabolic Synd 2013; 2:126. Doi: 10.4172/21670943.1000126 .
11. Musa DI, Toriola AL, Monyeki MA, Lawal B. Prevalence of childhood and adolescent overweight and obesity in Benue State, Nigeria. Tropical Medicine and International Health 2012; 17: 1369 1375.

12. Akodu SO, Diaku- Akinwumi IN, Njokanma OF. Obesity - Does it occur in Nigerian children with sickle cell anemia. Pediatric Hematology Oncology 2012;29:358 364.

13. Dong $\mathrm{C}$, Wang $\mathrm{S}$, Price RA. Interacting genetic loci on chromosomes 20 and 10 influence extreme human obesity. Am J Hum Genet 2003;72: $115-124$.

14. Scott A, Ejikeme CS, Clottey EN, Thomas JG. Obesity in sub- Saharan Africa: development of an ecological theoretical framework. Health Promotion International Advance Access 2012; 1 - 13. Doi: 10.1093/heapro/das038.

15. Caballero B. A nutrition paradox: underweight and obesity in developing countries. $N$ Engl J Med 2005;352: 1533- 1544 .

16. Centers for Diseace Control and Pevention. CDC Features: Obesity and Genetics, 2010. Available from: http//.www.cdc.gov/ Features/Obesity. Accessed 31th October 2010.

17. Wang K, Li W, Zhang CK, Zuoheng W, Glessner JT, Grant SFA, Zhao H, Hakonarson H, Price RA. A genome - wide association study on obesity and obesity related traits. PLOS ONE 2012;7: 10.1371.

18. Ravussin E, Valencia ME, Esparza J, Benneth PH, Schulz LO. Effects of traditional lifestyles on obesity in Pima Indians, Diabetes care 1994:17: 1067 - 1074.

19. Oken O, Gillman MW. Fetal origins of obesity. Obesity Research 2003; 11: 496- 506.
20. Zang S, Rattanatray L, Janna L, Morrison JL, Nicholas LM, Lei L, Mcmillen C. Maternal obesity and the early origins of childhood obesity: weighing up the benefits and costs of maternal weight loss in the periconceptional period for the offspring. Experimental Diabetes Research 2011, Article ID 585749,10pages.

21. Von Kries R, Toschke AM, Koletzko B Sikker W Jr. Maternal smoking during pregnancy and childhood obesity. Am J Epidemiol 2002;156:954-961.

22. Arenz S, ruckerl R, Koletzko B, von KR. Breast feeding and childhood obesity: a systematic review. Int J obes Relat Metab Disorder 2004;28:1247 - 1256.

23. Owen CG, Martin RM, Whincup PH, Smith GD, Cook DG. Effect of infant feeding on the risk of obesity across the life course: a quantitative review of published evidence. Pediatics 2005; 115:1367 -1377.

24. Harder T, Bergmann A. Duration of breastfeeding and risk of overweight: a meta- analysis. Am J Epidmiol 2005;162:397 -403.

25. Kuo AA, Ineklas M, [...], Halfan $\mathrm{N}$. Introduction of solid food to young infants. Maternal Child Health J. 2011;15:1185-1184.

26. Norris JM, Barriga K, Klingensmith G, Hoffman M, Eisenbarth GS, Erlich HA, Rewers M. Timing of initial cereal exposure in infancy and risk of islet autoimmunity. J Americ Med Associ 2003;290:1713- 1720.

27. Huh SY, Rifas -Shiman SL, Gillman NW. Timing of solid food introduction and risk of obesity in preschool - aged children. Pediatrics 2011; 127: e544- e551. 
28. Finkelstein JW, Anders TF, Sacher EJ, Roffwarg HP, Hellman LD. Behavioral state, sleep stage and growth hormone levels in human infants. J Clin Endocrinol Metab 1971, 32: 368 -371.

29. Lampl M, Johnson MC. Infant growth in length follows prolonged sleep and increased naps. Sleep 2011;34: 641- 650.

30. Herbst CM, Tekin E. Child care subsidies and childhood obesity. Discussion paper No. 4255, June 2009. Available from: http://www. ftp.iza.org/dp4255.pdf. Accessed: 30th June, 2013.

31. Denninson BA, Russo TJ, Burdick PA, Johnkins PL. An intervention to reduce television viewing by preschool children. Arch Pediatr Adolesc Med 2004; 158:170 -176.

32. Zimmerman FJ, Bell JF. Association of television content type and obesity in children. Am J Public Health 2010; 100:334 - 340.

33. Spiegel K, Tasali F, Leprodult R, Cauter E. Effects of poor and short sleep on glucose metabolism and obesity risk. Nat Rev Endocrinol 2009;5:253- 261.

34. Chaput J, Lambert M, Gray Donald K, McGrath JJ, Tremblay MS, O'Loughlin J, Trmblay A. Short sleep duration is independently associated with overweight and obesity in Quebec children. Can J Public Health 2011;102:369-374.

35. Malik VS, Schulze MB, Hu FB. Intake of sugar - sweetened beverages and weight gain: a systematic review. Am J Clin Nutr 2006; 84:274-288.

36. Ludwig DS, Peterson KE, Gortmaker SL. Relation between consumption of sugar - sweetened drinks and childhood obesity: a prospective, observational analysis. Lancet 2001; 357: 505- 508.

37. Jurgens H, Hass W, Castaneda TR, et al. Consuming fructose - sweetened beverages increases body adiposity in mice. Obes Res 2005; 13: 1146:1156.

38. Havel PJ, Dietary fructose: implications for dysregulation of energy homeostasis and lipid/ carbohydrate metabolism. Nutr Rev 2005; 63: 133- 157.

39. Havel PJ. Control of energy homeostasis and insulin action by adipocyte hormones: leptin, acylation stimulating protein, and adiponectin. Curr Opin Lipidol 2002; 13:51- 59.
40. Consider ethnic, cultural influences on childhood obesity. Available from: http://www.healio.com/ endocrinology/pediatricendocrinology/news/print/ Accessed: $4^{\text {th }}$ December, 2014.

41. Caprio S, Daniels SR, Drewnowski A, Kaufman FR, Palinaks LA, Rosenbloom AL, Schwimmer JB. Influence of race, ethnicity, and culture on childhood obesity: implications for prevention and treatment. Diabetes Care 2008.

42. Dinsa GD, Goryakin Y, Suhrcke M. Obesity and socio- economic status in developing countries: a systematic review. Obes Res 2012; 13: 1067 -1079.

43. Wang Y, Beydoun MA. The obesity epidemic in the United StatesGender, age, socioeconomic, racial/ethnic, and geographic characteristics: A systematic review and meta - analysis. Epidemiol Rev 2007; 29:6-28.

44. Chukwuonye II, Chuku A, [...], Ogah OS. Socioeconomic status and obesity in Abia State, South East Nigeria. Diabetes Metab Syndr Obes 2013; 6:371- 378.

45. Rahman S, Islam MT, Alam DS. Obesity and overweight in Bangladesh children and adolescents: a scoping review. BMC Public health 2014; 14:70. Available from: http://www.biomedcentral. com/1471-2458/14/70.

46. Azambuja APO, Netto - Oliveira ER, de Oliveira AAB, dos Anjos Azambuja M, Rinaldi W. Prevalence of overweight/obesity and economical status of school children. Rev Paul Pediatr 2013; 31 . $166-171$.

47. McMichael AJ. The urban environment and health in a world of increasing globalization: issues for developing countries. Bull Wrld Hlth Organ 2000; 78: 1117 -1126.

48. Drewnowski A, Popkin B. The nutrition transition: new trends in the global diet. Nutrition Revolution 1997;55:31- 43.

49. Global recommendation on physical activity for health. Available from: http://www. Whqlibdoc. who.int/publications/ 2010/97892 41599979_eng.pdf. Accessed: $2^{\text {nd }}$ October, 2014.

50. Resolution WHA57.17. Global strategy on diet, physical activity and health. In: Fifty - seventh World Health Assembly, Geneva, 17 - 22 May 2004. Resolutions and decisions, annexes. Geneva, World Health Organization, 2004.
51. Double burden of obesity and malnutrition in Western Sahara refugees. Available from: http:// www.ennonline.net/pages/ pdf/4340. Accessed: 1st October, 2014.

52. The double burden of malnutrition in India. Available from: http:// www.ftp.fao/docrep/fao/009/ ao442e/a0442r01.pdf. Accessed: 30th August, 2014.

53. Nirmala A, Reddy RM, Reddy PP. Genetics of human obesity: an overview. Int. J Human Genet 2008;8: 217 - 226.

54. Skelton JA, Rudolph CD. Overweight and obesity. In:Kliegman RM, Jenson HB, Behrman RE, Stanton BF (eds) Nelson textbook of pediatrics $18^{\text {th }}$ ed. Philadelphia (USA), Saunders Elsevier, 2007: $232-242$.

55. Eluhu M, Abed Y, Rahmat A, Ranneh Y, Ali F. Epidemiology of obesity in developing countries: challenges and prevention. Global Epidemic Obes 2014;2:2. Available from: http://www. dx.doi.org/10.7243/ 2052- 5966-22. Accessed: $3^{\text {rd }}$ October, 2014.

56. Ganong WF. Central regulation of visceral function. In: Review of medical physiology, McGraw Hill Publication, New York, 2000.

57. Srivastava N, Lakhan R, Mittal B. Pathophysiology and genetics of obesity. Indian J Experimental Biol 2007;45:929 -936.

58. Krebs NF, Hims JH, Jacobson D, Nicklas TA, Guilday P, Styne D. Assessment of child and adolescent overweight and obesity. Pediatrics 2007; 120: S193. (DOI: 10.1542/ peds.2007-232D). Available from: http://www.pediatrics. aappublications.org/content/120/supplement_4/s193.full.html. Accessed: 5th October, 2014.

59. Krebs NF, Jacobson MS. American Academy of Pediatrics. Prevention of pediatric overweight and obesity. Pediatrics 2003;112: 424430.

60. Kuczmarski RJ, Ogden CL, Grummer - strawn LM, et al. CDC Growth charts: United States. Adv Data 2000; 314: 1-27.

61. World Health organization growth standards are recommended for use in the United States for infants and children 0 to 2 years of age. Available from: http://www. cdc.gov/ growthcharts/who_charts.htm. Accessed: $5^{\text {th }}$ October, 2014.

62. Thompson DL. The costs of obesity: what occupational health nurses need to know American Association of Occupational Health Nurses AAOHN Journal 2007; 55: 265 270 . 
63. Popkin BM, Horton S, Kim S, Mahal A, Shuigao J. trends in diet, nutritional status, and diet - related non -communicable diseases in China and India: The economic costs of the nutrition transition. Nutr Rev 2001; 59:379- 390.

64. Aikins A, Boynton P, Atanga LL. Developing effective chronic disease interventions in Africa: insights from Ghana and Cameroon. Globalization and Health 2010;6:6. Available from: http:// www.globalization and health.com/content/6/1/6. Accessed: $1^{\text {st }}$ December, 2014.

65. Willis M. orthopedic complications of childhood obesity. Pediatric Physical Therapy 2004;16:230 -235 .

66. Bryner J. Childhood obesity takes psychological toll, too. Available from: http://www. livescience. com/6126-childhood-obesity-takes -psychological. Accessed: $4^{\text {th }}$ October, 2014.

67. Obesity prevention source- economic costs. Available from: http://www.hsph.harvard.edu/ obesity-prevention-source/obesityconsequences/economic/. Accessed: $8^{\text {th }}$ December, 2014
68. The obesity stigma. Available from: http://www.psychology today.com/blog/food-junkie/201306/ the-obesity-stigma. Accessed: 5th October, 2014.

69. Cawley J, Meyerhoefer C. The medical care costs of obesity: an instrumental variables approach. $J$ Health Econ. 2012; 31:219-30.

70. Nobre LN, Silva KC, Ferreira SE, Moreira LL, Lessa A, Lamounier JA et al. Early determinants of overweight and obesity at 5 years old in preschoolers from inner of Minas Gerais, Brazil. Nutr Hosp. 2013; 28:764-771.

71. Agho KE, Dibley MJ, Odiase JI, Ogbonmwan SM. Determinants of exclusive breastfeeding in Nigeria. BMC pregnancy child health 2011; 11:2. [Online]. Doi:10.1186/14712393-11-22011.

72. Nobre LN, Silva KC, de Castro Fereira SE, Moreira LL, Lessa AC, lamonnief JA, Franceschini SC. Early determinants of overweight and obesity at 5years old preschoolers from inner of Minas Gerals, Brazil. Nutr Hosp 2013; 28:764- 771 .

73. Oldridge NB. Economic burden of physical inactivity: health care cost associated with cardiovascular disease. Eur J Cardiovasc Prev Rehabil 2008; 15:130-139.
74. Goran MI, Reynolds KD, Lindquist $\mathrm{CH}$. Role of physical activity in the prevention of obesity in children. International Journal of Obesity 1999; 23, Suppl 3: S18-S33.

75. American Academy of Pediatrics. Media Use by Children Younger Than 2 Years. Pediatrics 2011; 128: pp. 1040 -1045.

76. Hall V, Thomsen R, Henriksen O, Lohse N. Diabetes in sub-Saharan Africa 1999-2011: epidemiology and public health implications. A systematic review. BioMed Central Public Health 2011; 11: 564. [Online]. Doi: 10.1186/1471-2458 -11-564.

77. Iughetti L, China M, Berri R, Preieri B. Pharmacological treatment of obesity in children and adolescents. Present and future. Journal of obesity 2011; Article ID 928165, 13 Pages. Available from: http://dx.doi.org/10.1155/ 2011/ 98165. Accessed: 2nd November, 2014.

78. Michalsky M, Reichard K, Inge T, Pratt J, Lenders C. ASMBS Pediatric committee best practice guidelines. Surgery Obesity Related diseases 2012;8: 1-7. 